\section{Implementation science takes baby steps in infants with bronchiolitis}

\author{
Steve Cunningham, ${ }^{1}$ Hilary Pinnock ${ }^{2}$
}

Bronchiolitis, the annual winter endemic of acute viral lower respiratory tract illness in infants, is challenging for hospitals with overfull paediatric wards, for general practitioners worried about not spotting the infant at risk and for sleep-deprived parents looking after a sick child. The National Institute for Health and Care Excellence (NICE) Bronchiolitis guideline, published in 2015, ${ }^{1}$ highlights 'red flags' and lists ineffective treatments which 'should not be used', citing abundant clinical trials.

In this journal, Carande and colleagues ${ }^{2}$ gauge the effect of the guideline publication on management in general practice. There were some shifts towards better practice in the (self-selected) general practitioner (GP) respondents, though improvement was incremental rather than transformational, as is common to new guidelines. ${ }^{3}$

Nearly three-quarters of respondents routinely used oximetry for the assessment of a child with acute bronchiolitis. Measuring oxygen saturation with an age-appropriate device has been widely promoted as essential in the assessment of patients of any age with acute lower respiratory symptoms and/or signs. Implementing this strategy across primary care should be encouraged: significant hypoxaemia may not be evident on clinical examination alone ${ }^{4}$ and oximetry reduces individual risk. However, identification of borderline hypoxaemia may induce clinical uncertainty ${ }^{5}$; a possible reason why GPs reported that the NICE guideline did not reduce referral rates. Studies informing the safe, efficient use of pulse oximetry in primary care are required.

Of the 'do not use' medicines, half were prescribed as a safeguard against alternative diagnoses. In a disease characterised by 'crackles and/or wheeze on auscultation', two differential diagnoses

\footnotetext{
${ }^{1}$ Department of Child Life and Health and MRC Centre for Inflammation Research, The University of Edinburgh, The Queen's Medical Research Institute, Edinburgh, UK ${ }^{2}$ Allergy and Respiratory Research Group, Usher Institute of Population Health Sciences and Informatics, The University of Edinburgh, Edinburgh, UK
}

Correspondence to Professor Steve Cunningham, Department of Child Life and Health and MRC Centre for Inflammation Research, The University of Edinburgh, The Queen's Medical Research Institute, Edinburgh EH16 4TJ, UK; steve.cunningham@nhs.net predominate. Crackles consistent with bacterial pneumonia (requiring antibiotics) and wheeze associated with 'early' asthma (warranting bronchodilators and steroids, though asthma guidelines caution that steroids are ineffective in viral associated wheeze). ${ }^{6}$ Supporting front-line staff to have greater confidence in the diagnosis of bronchiolitis and lack of alternative diagnoses is likely to be more effective than a recommendation in a bronchiolitis guideline that a drug is ineffective.

Wheeze is distressing for parents (even if the child is not distressed), and, understandably, clinicians may be tempted to suggest symptomatic relief with bronchodilators, despite objective evidence of ineffectiveness. Previous prescribing experience (eg, in older siblings) and a perception that it is a safe drug may contribute to the decision to prescribe a bronchodilator. Considerably more disconcerting is the prescribing of systemic corticosteroids to one in five children which, particularly in repeated dosing, carries evidence of harm. A third of the GPs surveyed believed there was evidence of benefit for their prescribing choice, despite lack of benefit identified in the guideline.

Proactive implementation requires attention, not only to informing and enabling change in professional behaviour, but also to the support required by parents and the organisational and societal context in which change is being promoted. A prescription for antibiotics, once the norm, is now relatively uncommon (5\%)-in secondary care it is frequently $30 \% .^{3}$ Carande's finding that only $7 \%$ considered that the guideline had contributed to a change in their behaviour points to the complexity of improving clinical practice. Public health campaigns ${ }^{7}$ and a gradual shift in parental perception of the (lack of) role of antibiotics in acute viral infection is more likely to have facilitated clinical decisions not to prescribe than any disease-specific guidelines.

Implementation strategies are more effective when tailored to address specific factors pertinent to the condition, and aligned with the perceptions of parents, professionals or organisational context. ${ }^{8}$ A third of the GP respondents used a locally adapted guideline, echoing the known benefits of local champions in supporting implementation. ${ }^{9}$
Other strategies may include templates in the electronic health record that could provide timely guidance during a consultation for suspected bronchiolitis, enhancing diagnostic confidence, stratifying risk and providing clear parent-directed statements on ineffective treatments. While there was an improvement $(38 \%-46 \%)$ in the proportion of GPs providing written advice to parents, use of the leaflets (ie, NICE Bronchiolitis information for parents ${ }^{10}$ ) might be increased by providing a link from the electronic health record to facilitate downloading during consultation.

The NICE Bronchiolitis guidelines have set out simple, clinically and economically efficient recommendations to support the annual endemic. Carande and colleagues identify that implementation is moving in the right direction but still has some way to go. Implementation strategies such as national promotion of oximetry to assess acute respiratory illness, local healthcare organisations supporting integrated templates for respiratory consultations in infants and locally adaptable resources for parents could improve the care infants with bronchiolitis receive whether in primary care, emergency departments or on hospital wards.

Contributors Both authors contributed equally to the development and final version of the manuscript.

Competing interests SC was chair of the NICE Bronchiolitis guideline development group. HP has no competing interests to declare.

Provenance and peer review Commissioned; externally peer reviewed.

(C) Article author(s) (or their employer(s) unless otherwise stated in the text of the article) 2018. All rights reserved. No commercial use is permitted unless otherwise expressly granted.

\section{Check for updates}

To cite Cunningham S, Pinnock H. Thorax 2018;73:599-600.

Accepted 5 February 2018

Published Online First 20 February 2018

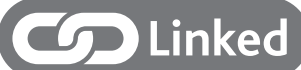

- http://dx.doi.org/10.1136/thoraxjnl-2017-211180

Thorax 2018;73:599-600.

doi:10.1136/thoraxjnl-2017-211455

\section{REFERENCES}

1 National Institute for Health and Care Excellence. Bronchiolitis: diagnosis and management in children (Clinical guideline ng9), 2015

2 Carande EJ, Cheung CR, Pollard AJ, et al. Change in viral bronchiolitis management in primary care in the 
UK after the publication of NICE guideline. Thorax 2018;73:674-6.

3 Parikh K, Hall M, Teach SJ. Bronchiolitis management before and after the AAP guidelines. Pediatrics 2014;133:e1-7.

4 Zhang L, Mendoza-Sassi R, Santos JC, et al. Accuracy of symptoms and signs in predicting hypoxaemia among young children with acute respiratory infection: a meta-analysis. Int $J$ Tuberc Lung Dis 2011:15:317-25.

5 Quinonez RA, Coon ER, Schroeder AR, et al. When technology creates uncertainty: pulse oximetry and overdiagnosis of hypoxaemia in bronchiolitis. BMJ 2017;358:j3850.

6 SIGN/BTS. British guideline on the management of asthma (QRG153). $2016 \mathrm{http}: / / w w w . s i g n . a c . u k / s i g n-$ 153-british-guideline-on-the-management-of-asthma. html (accessed Jan 2018).

7 Saam M, Huttner B, Harbarth S. Health organisation expert committee on the selection and use of essential medicines policy. Evaluation of antibiotic awareness campaigns. http://www.who.int/selection_medicines/ committees/expert/21/applications/s6_antibiotic_ awareness_campaigns.pdf (accessed Dec 2017).
8 Baker R, Camosso-Stefinovic J, Gillies C, et al. Tailored interventions to address determinants of practice. Cochrane Database Syst Rev 2015;4:CD005470.

9 Flodgren G, Parmelli E, Doumit G, et al. Local opinion leaders: effects on professional practice and health care outcomes. Cochrane Database Syst Rev 2011;8:CD000125.

10 National Institute for Health and Care Excellence. Bronchiolitis in children: information for parents. 2015 https://www.nice.org.uk/guidance/ng9/resources/ bronchiolitis-in-children-pdf-82789906885 (accessed Jan 2018). 